\title{
Utilization of Crude Glycerin from Biodiesel Production: A Field Test of a Crude Glycerin Recycling Process
}

\author{
Hayato Tokumoto, Hiroshi Bandow, \\ Kensuke Kurahashi and Takahiko Wakamatsu \\ Additional information is available at the end of the chapter
}

http://dx.doi.org/10.5772/52171

\section{Introduction}

\subsection{Background}

Worldwide, increasing quantities of biodiesel fuel (BDF) are produced, along with bioethanol. The production of BDF generates glycerin (also known as glycerol) as a by-product. Because alkaline metal oxides or alkaline hydroxides are commonly used as catalysts for the transesterification of vegetable oils with methanol, the glycerin stream is strongly alkaline, and therefore must be neutralized, demineralized, rinsed with water, and dried before glycerin is combusted. This has been a barrier to the popularization of BDF [1-3].

Osaka Prefecture University (abbreviated as OPU) in Sakai, Japan, is promoting a "Campus Zero Emissions" project, intended to recycle the resources within the campus. We have a benchscale methane fermentation plant and BDF production plant based on ultrasound that is capable of producing BDF and methane from waste cooking oil [4-7] and food waste.

Methane fermentation is one of the main processes used for food waste (nitrogen and carbon mixtures) stabilization. High nitrogen concentration and $\mathrm{pH}$ inhibits growth of bacteria because of toxicity caused by high levels of ammonia. Microorganisms require carbon and nitrogen for metabolism, and the relationship between their amounts in organic materials is represented by the $\mathrm{C} / \mathrm{N}$ ratio. Optimum $\mathrm{C} / \mathrm{N}$ ratios in anaerobic digesters are between 20 and 30. A high $\mathrm{C} / \mathrm{N}$ ratio is an indication of rapid consumption of nitrogen by methanogens, and results in lower gas production. On the other hand, a lower $\mathrm{C} / \mathrm{N}$ ratio causes ammonia accumulation and $\mathrm{pH}$ values exceeding 8.5 , which is toxic to methanogenic bacteria. Optimum $\mathrm{C} / \mathrm{N}$ ratios in digester contents can be achieved by mixing materials with high and low $\mathrm{C} / \mathrm{N}$ ratios, such as the raw glycerin byproduct of BDF production. 
One of the authors, Tokumoto, has filed three patent applications regarding a leading-edge technology that allows the fermentation of strongly alkaline waste glycerin using anaerobic microorganisms, without additional processes. This technology is expected to compete with fermentation technology that uses a microorganism with high glycerin degradation ability. However, the latter is, in general, based on the selection of the most favorable individually cultivated microorganism system from a wide variety of individually isolated fungi. The cost of an operation that utilizes such delicate microorganisms is high and this is one of the barriers to commercialization of the system (Figure 1) [8-12]. Using high-level experience in microbiological control, our project is working towards the establishment of a new process based on a low-cost, combined cultivation system.

<Advantages Provided by the Use of a Combined Cultivation System>

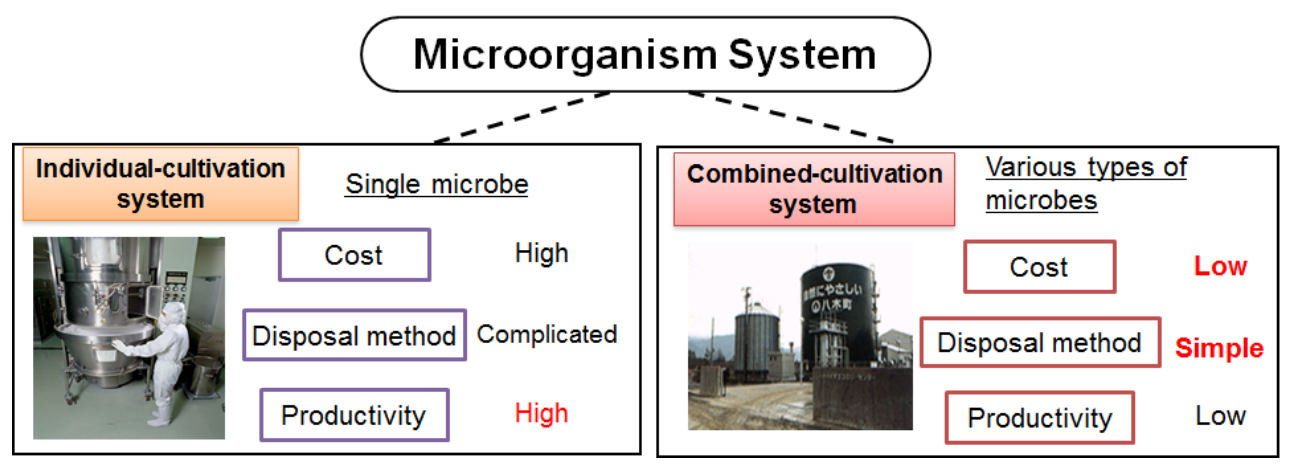

Figure 1. Comparison between individual- and combined-cultivation systems

\subsection{Purpose}

The campus zero-emission project is intended to establish the business model for OPU's resource recycling process using waste cooking oil. In this model, we produce BDF from waste cooking oil discharged from the dining halls on campus and generate methane from the glycerin by-product to supply fuel for motorcycles, vehicles, and electric power facilities [13-14]. This research activity will result in verification tests based on about 10,000 students and teaching/clerical staff members as monitors, and then develop the test results into a comprehensive recycling process for waste cooking oil.

Commercial-scale plants will be standardized at the end of this project, based on the operational data from the methane fermentation plant and utilization facilities (motorcycles, other vehicles, and electric power facilities) shown in the figure below. 


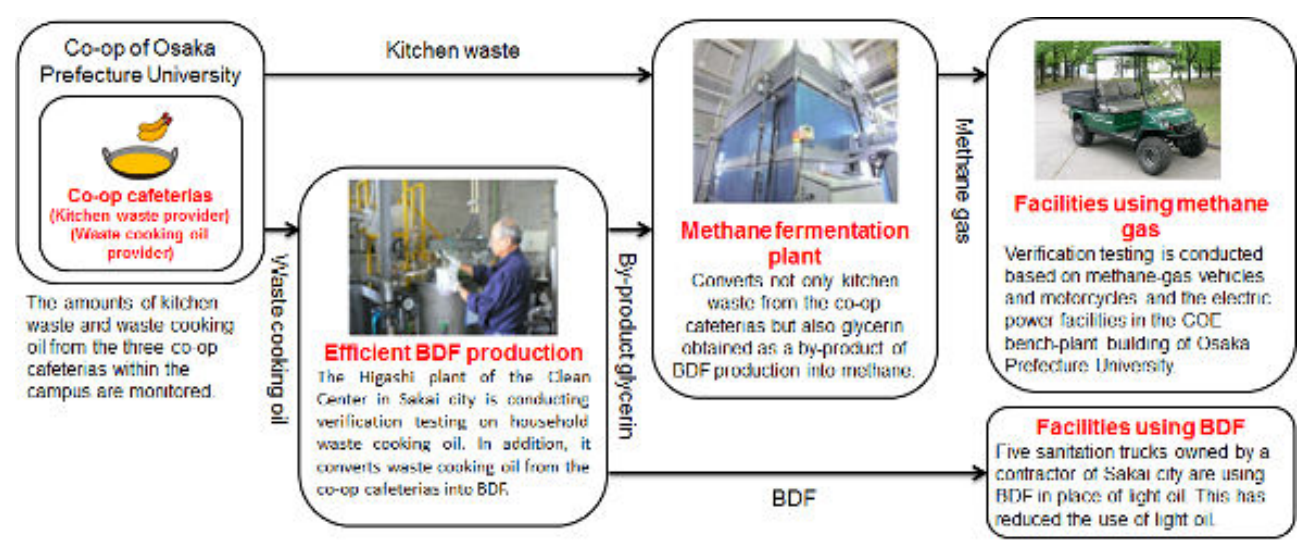

Figure 2. Entire experiment flow chart

\section{Results and discussion}

\subsection{Methane fermentation reactor}

The methane fermentation plant has only one fermenter, with a fermentation vessel volume of $10 \mathrm{~m}^{3}$ and an operating capacity of $5 \mathrm{~m}^{3}$. From startup, the plant used bean curd lees as a fermentation substrate (fermentation feedstock for breeding microorganisms and generating methane) to achieve stable operation. We then added another fermentation substrate - part of the kitchen waste from the OPU's co-op cafeteria. After stable operation was achieved, we then added waste glycerin, the by-product generated during BDF production.

\subsection{Operational testing on the fermentation plant}

\subsubsection{Alkali considerations of the microorganism fermentation plant}

The figure below shows the correlation between the amount of gas generated and the raw material disposal rate.

We purchased seed sludge from the methane fermentation plant of the Bioecology Center in Yagi Cho, Kyoto Prefecture and charged this into the fermenter in our methane fermentation plant. After the startup (neutralization) process, we used bean curd lees as a fermentation substrate, which resulted in favorable biogas production after about 10 days (Figure 3). In this case, we observed a positive correlation between the amounts of bean curd lees disposed of and the biogas generated. From May 12 to June 5, the amount of generated biogas per unit amount of bean curd lees was $0.68 \mathrm{~m}^{3} / \mathrm{kg}$, calculated by the least-squares method (Figure 3). 


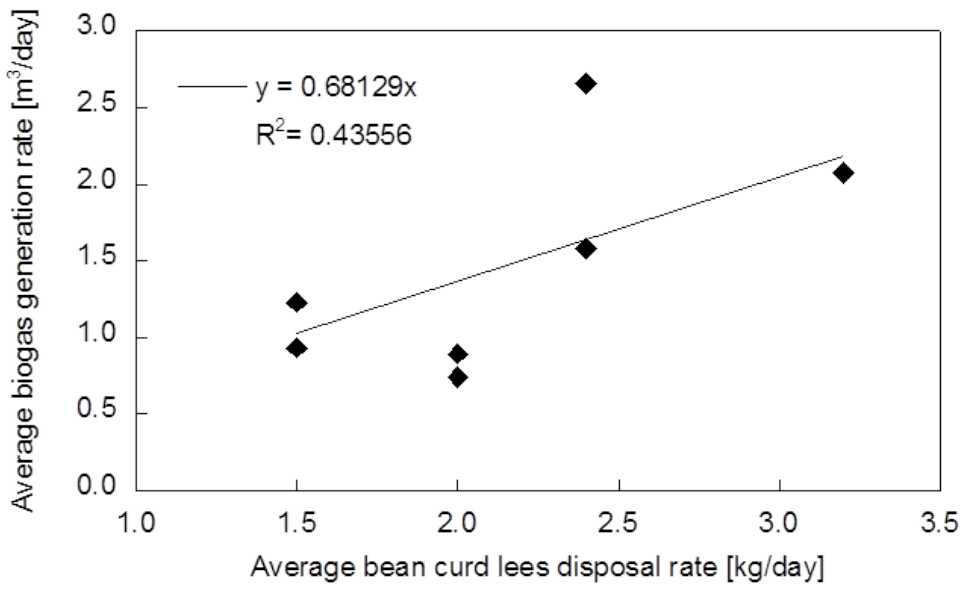

Figure 3. Correlation between the amounts of gas generated and bean curd lees disposal rate

\subsubsection{Biogas from co-op waste}

Temporal changes in the amounts of biogas produced after the kitchen waste from the co-op cafeteria was added are shown in Figure 4.

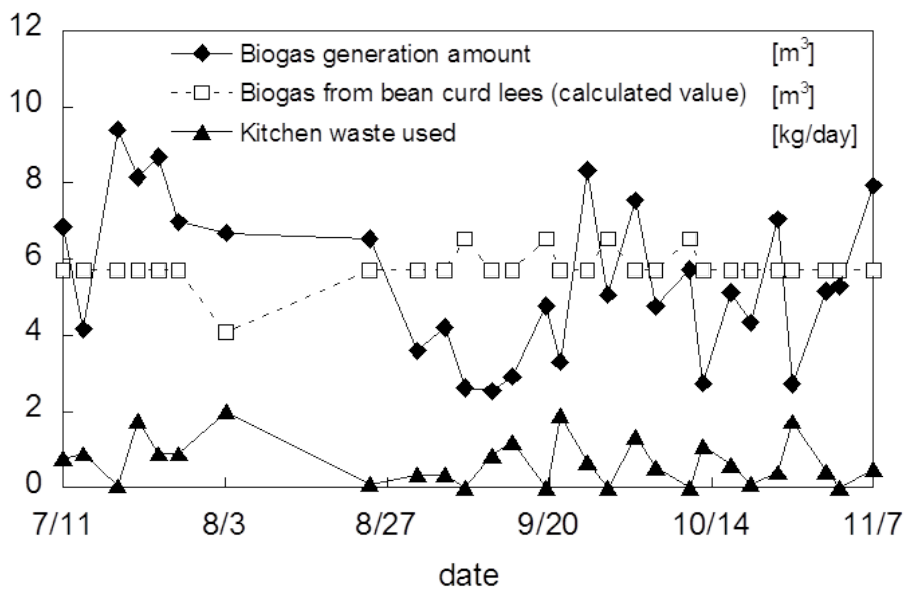

Figure 4. Amount of biogas generated from kitchen waste discharged from the co-op cafeteria

The amounts of biogas generated shown in Fig. 4 are actual measured values. The amounts of biogas from the bean curd lees were obtained by multiplying the biogas generation rates calculated in Figure 3 by the amount of bean curd lees. The subtraction of these values may 
result in negative values in some cases. For this reason, the figure does not indicate the amounts of biogas from the kitchen waste discharged from the co-op cafeteria, but only the amounts of waste added.

In producing these results, we successfully disposed of co-op waste without destabilizing the biogas production at the plant, which provided a favorable biogas production even using coop kitchen waste. In this case, we successfully converted a maximum of $2 \mathrm{~kg}$ co-op kitchen waste into biogas per day.

The results, however, also indicated that the kitchen waste delivered a conversion efficiency lower than that for bean curd lees alone. Bean curd lees are vegetable-protein food and contain significant nitrogen and exhibit a low $\mathrm{C} / \mathrm{N}$ value. The $\mathrm{C} / \mathrm{N}$ value is usually regarded as an index of the favorability of substrates towards anaerobic fermentation [15], and the low value for bean curd lees suggests that the existence of the low $\mathrm{C} / \mathrm{N}$-value substrates, bean curd lees, in this system could decrease the reactivity of the microorganisms producing biogas. It should be noted, however, that in the long-term, increases in the use of co-op waste lead to gradual increases in the amount of biogas generated.

Figure 5 shows the monthly number of cafeteria users in 2011. A university-specific trend was observed, in that the number of users decreased during the long vacation period in August and September. A similar trend among the kitchen waste used and amount of biogas generated in Figure 4 and the number of the cafeteria users in Figure 5 indicates that the gas production amount is strongly correlated with the number of cafeteria users. Consequently, the largest influence is the decrease in the amount of organic substances contained in the kitchen waste. When the number of users was stable in September and October, the biogas production stabilized, meaning that the plant seems to provide stable operation as a whole. With these behaviors in mind, this research is characterized by the fact that investigating the amount of waste enables the estimation of the performance of the fermentation plant, based on the number of users of the dining facility or facilities in the business place.

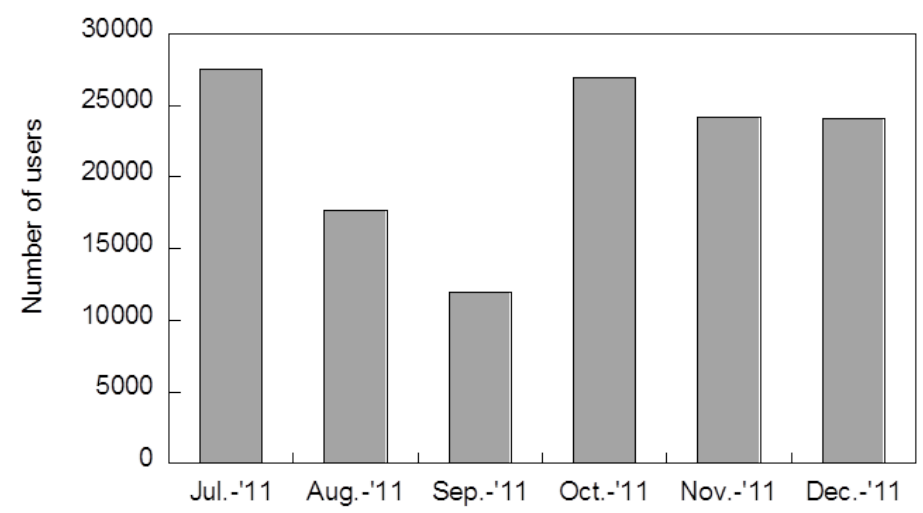

Figure 5. Number of co-op cafeteria users 


\subsubsection{Converting waste glycerin into biogas}

The amounts of biogas achieved when bean curd lees, kitchen waste, and waste glycerin were used as substrates are shown in Figure 6.

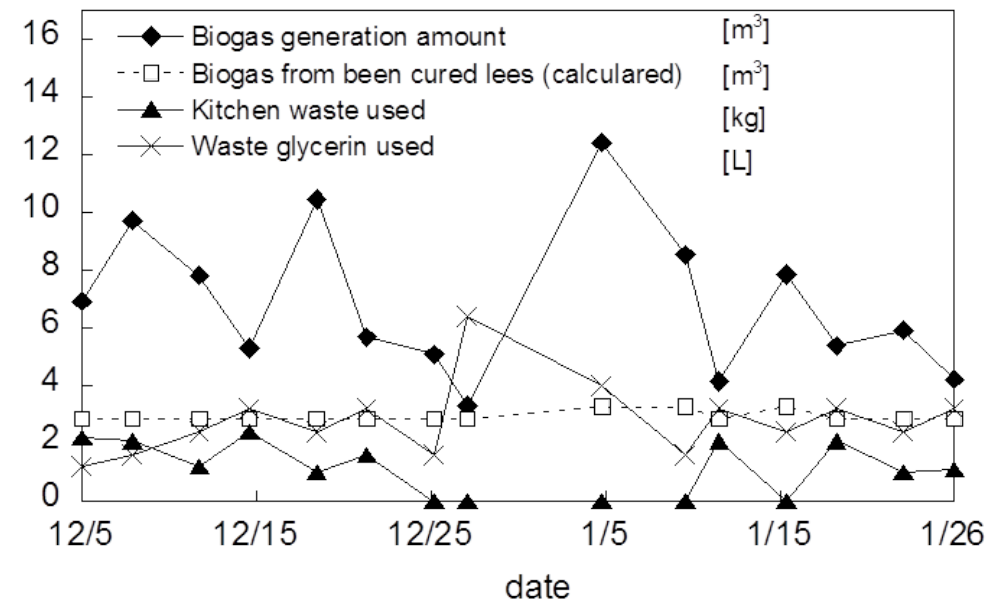

Figure 6. Amounts of biogas generated from bean curd lees, kitchen waste, and waste glycerin

The amounts of biogas shown are actual measured values. The amounts of biogas produced from the bean curd lees were obtained by multiplying the biogas generation rates calculated in Figure 3 by the amount of bean curd lees. For the kitchen waste and waste glycerin, the figure indicates the amounts used.

The amount of waste glycerin is correlated with the amount of biogas generated, whereby the addition of glycerin significantly increases the amount of biogas. Therefore the disposal of waste glycerin in this process has significant advantages. It is estimated that the biogas generation rate per unit amount of glycerin was $1.63 \mathrm{~m}^{3} / \mathrm{kg}$ on average. This is about 2.5 times the biogas generation rate when bean curd lees alone were used. It was also observed that about $2 \mathrm{~kg}$ of co-op kitchen waste per day were steadily decomposed by fermentation, as seen above. The operation continued steadily for about a month. In addition, the amounts of bean curd lees, kitchen waste, and waste glycerin we used this time were small compared with the operating capacity of the fermentation vessel, and the full capacity has not yet been used.

\subsubsection{Estimated reduction in $\mathrm{CO}_{2}$ emissions}

The disposal flow and the calculated reduction in $\mathrm{CO}_{2}$ emissions per unit amount disposed are shown in Figure 7. 


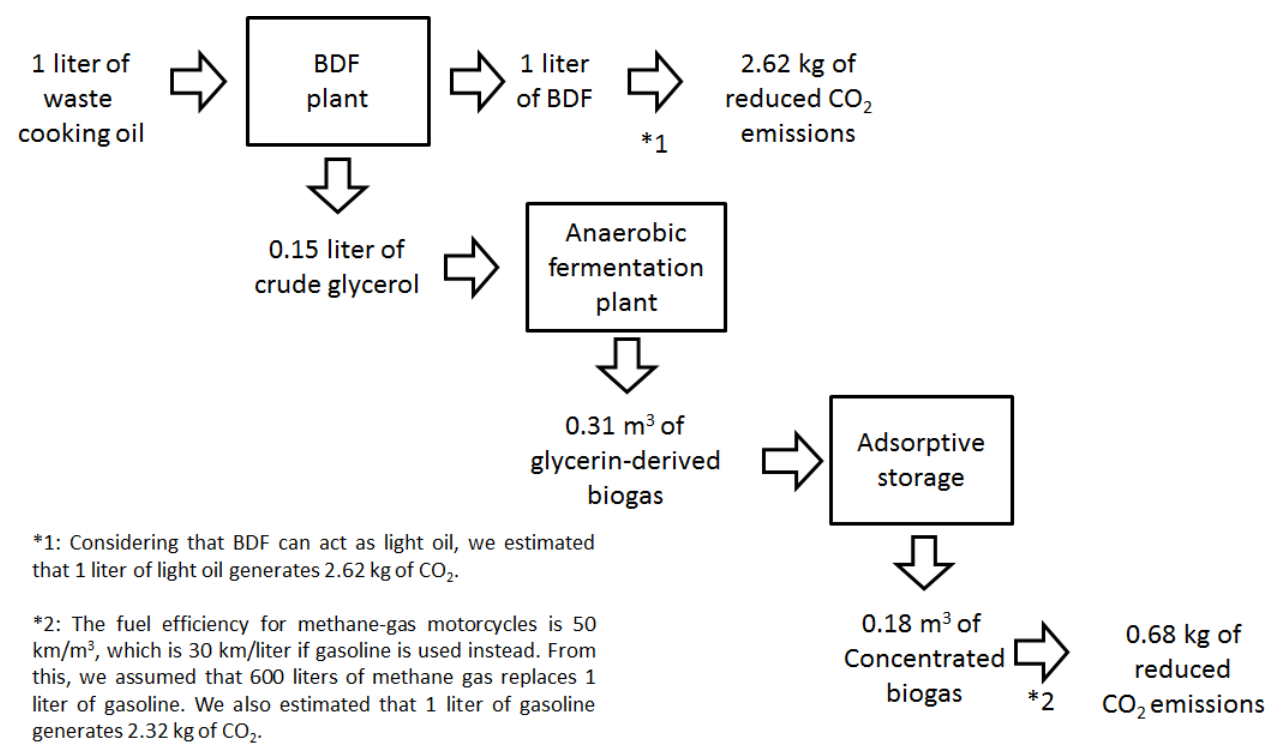

Figure 7. Disposal flow and reduced $\mathrm{CO}_{2}$ emissions

Because waste cooking oil is a plant-derived organic substance, it is possible to estimate the reduction in $\mathrm{CO}_{2}$ emissions based on carbon neutrality. For simplicity, we ignored the $\mathrm{CO}_{2}$ emissions associated with machine operation. We also assumed that we could treat BDF equally as an alternative to light oil. Furthermore, we considered that 600 liters of biogas can replace one liter of gasoline, based on the fuel efficiency of motorcycles. The definitions of $\mathrm{CO}_{2}$ emissions from fossil fuels were based on the guidelines from the Ministry of Environment [16].

The disposal of glycerin at the anaerobic fermentation plant effectively reduces $\mathrm{CO}_{2}$ emissions by more than $30 \%$ compared with waste cooking oil wholly incinerated, without additional treatment. When glycerin is incinerated, a fossil fuel is normally used as a combustion aid. If this is taken into consideration, this method may have an even greater effect on reducing $\mathrm{CO}_{2}$ emissions. Only part of the kitchen waste from the co-op cafeteria is currently disposed of. Disposal of all kitchen waste will further reduce $\mathrm{CO}_{2}$ emissions.

While a long-term testing and verification period is required, it is expected that biogas generation from waste glycerin will further improve, providing a larger reduction in $\mathrm{CO}_{2}$ emissions.

\subsection{Biogas fuel conversion facilities}

The effective use of the biogas generated in the methane fermentation vessel as a fuel requires a system for temporarily storing the biogas, a system for concentrating the methane contained in the biogas, and facilities that can make effective use of the concentrated (refined) biogas. 
The concentrated methane gas can be used "as-is", if the required pressure is low. On the other hand, if it is used as a fuel for vehicles, then equipment for charging biogas into the vehicles is required. Figure 8 shows the biogas use flow chart. A description of the equipment we operated in this research is given below.

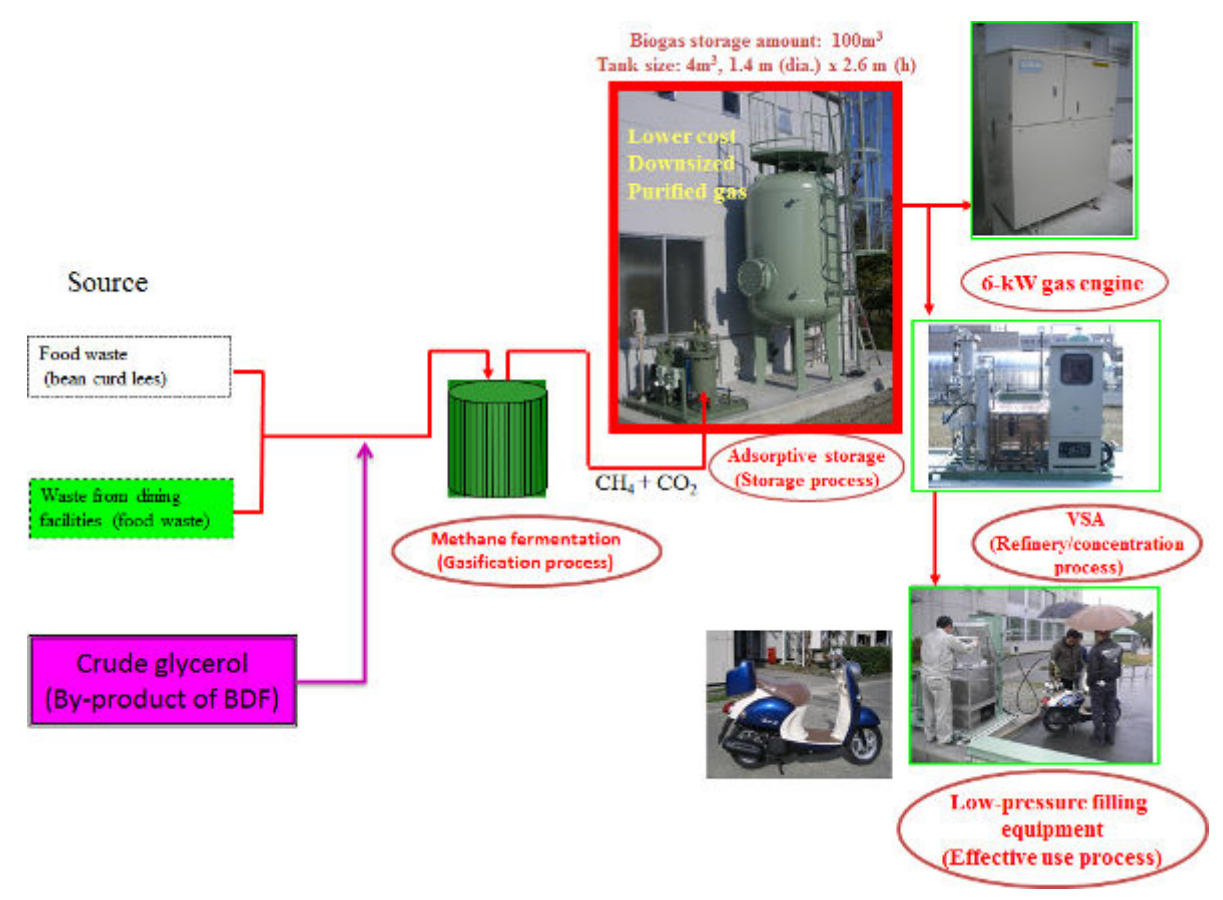

Figure 8. Biogas use flow chart

\subsubsection{Adsorptive biogas storage system}

\subsubsection{Principle}

The effective use of the biogas generated by methane fermentation requires a buffer tank for storing gas in order to make $100 \%$ use of the biogas, because it is difficult to balance the amount generated with usage at any one time.

In most cases currently, biogas is stored under a low pressure of a few hundred mm of $\mathrm{H}_{2} \mathrm{O}$, which is the gas pressure inside the fermentation vessel. However, this method can store only the same amount of gas as a gas tank. The storage of a larger amount of gas involves problems associated with size and equipment cost. To solve these problems, a method has been considered that fills the gas tank with a microporous absorbent to enable adsorptive storage of gas, allowing the storage of a large amount of gas at room temperature and under a relatively low pressure [17]. 
This method uses a phenomenon whereby methane, the major component of biogas, is physically absorbed in micropores of absorbents at a density close to that of its liquid state (Figure 9). This technology is expected to provide large-volume storage even under a relatively low pressure, because it even absorbs methane that is not liquefied by pressure. This new, attractive storage method, if commercialized, could provide safer storage of digestion gas with a lightly equipped device, according to purpose, and allow the transportation of biogas to other points of consumption, which is not common at the moment. In addition, it has the advantage that it can provide gas purification, which is required for effective use of biogas, through simultaneous adsorptive storage. Because biogas must be effectively stored in a limited area within the premises of the plant at this time, we used an adsorptive methane storage system.

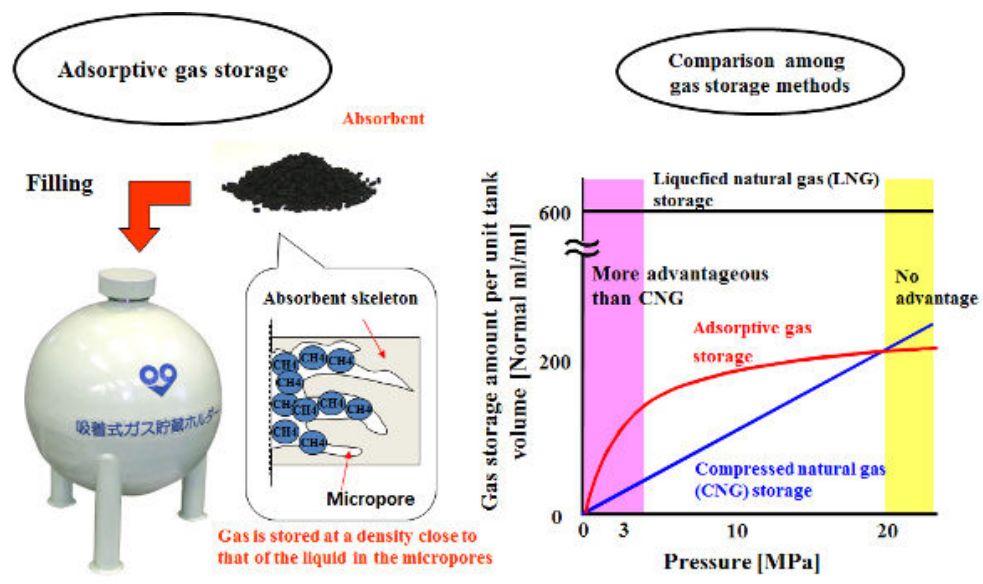

Figure 9. Principle of adsorptive storage

2.3.1.2. Device specifications (stationary large-capacity type, Figure 10)

- Type

Biogas-absorbent-filling-type, vertical cylindrical pressure tank

- Applicable laws and regulations

Construction Code for Pressure Vessels (second-class pressure vessels)

- Intended use

Adsorptive storage of biogas

- Gas storage capacity

Effective amount: approx. $100 \mathrm{Nm}^{3}$

activated carbon storage capacity of about $4 \mathrm{~m}^{3}$

- Dimensions 
1,700 mm (dia.) x 2,600 mm (H) (Trunk: 1,900 mm)

- Fluid

Refined biogas $\left(\mathrm{CH}_{4}: 60 \%, \mathrm{CO}_{2}: 40 \%\right)$

- Operating pressure

$0-0.75 \mathrm{MPa}(\mathrm{G})$

- Operating temperature

$10-50^{\circ} \mathrm{C}$

- Design temperature

$50^{\circ} \mathrm{C}$

- Design pressure

$0.8 \mathrm{MPa}(\mathrm{G})$

- Absorbent amount

Approx. 2.1 tons (coconut shell activated carbon)

- Main unit

SS400 (epoxy-coated inner surface)

- Ladder and handrail

SS400 and SGP

- Hanging ring SS400

- Foundation bolts and nuts SS400

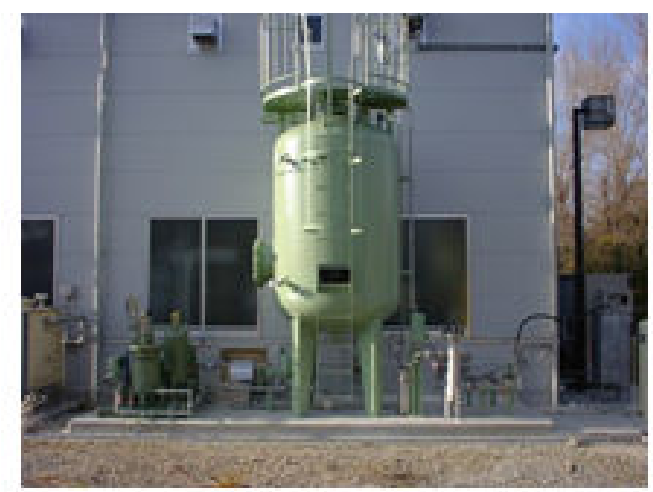

Figure 10. The adsorptive biogas storage system 


\subsubsection{Storage performance}

The storage performance depends significantly on the ambient air temperature, absorbent temperature, and the incoming and outgoing flow rates of the target gas, and is therefore difficult to measure accurately from the actual tank dimensions (Figure 10). For this reason, we used a small insulating container to measure the storage performance, similar to that of the actual tank, and evaluated the storage performance by rapidly filling it with $100 \%$ methane. We charged the gas at an absorbent temperature of $25^{\circ} \mathrm{C}$. It was verified that, with the activated carbon charged $100 \%$, the container can store $100 \mathrm{~m}^{3}$ of methane, approximately 25 times the tank capacity, if it operates in the range of $0-0.6 \mathrm{MPa}$.

\subsubsection{Adsorptive, isolated methane concentrating device}

\subsubsection{Principle}

In general, biogas generated in the methane fermentation vessel contains $\mathrm{CH}_{4}, \mathrm{CO}_{2}$, saturated $\mathrm{H}_{2} \mathrm{O}, \mathrm{H}_{2} \mathrm{~S}$, and trace quantities of organic components generated during the decomposition process. To make effective use of this gas, it is necessary to refine it (concentrate the methane, which will act as the fuel). If it is used as fuel for vehicles, the methane must be delivered at a purity of at least $95 \%$ and the water vapor must have a dew point of $-55^{\circ} \mathrm{C}$ or less.

The methods for refining biogas include pressure swing adsorption using an absorbent, the separation membrane technique using polymeric separation membranes, and the absorption technique using (alkaline) water. In this research, we used pressure swing adsorption (PSA) because it is able to produce methane and remove water [18].

As Figure 11 shows, the device uses an absorbent with a controlled micropore diameter to selectively absorb and remove carbon dioxide based on the difference in their molecular sizes. It also concentrates the methane and removes impurities. This means that using an absorbent with micropore sizes between the molecular sizes of methane and carbon dioxide, the device can separate methane, the major component of biogas, as well as carbon dioxide, water and impurities. At the same time, it also absorbs and removes water, which has a smaller molecular diameter than carbon dioxide. Note that the molecular sizes follow the order methane $>$ carbon dioxide $>$ water.

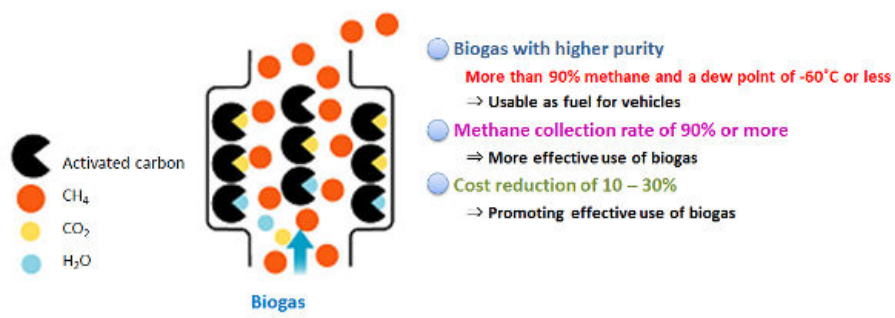

Figure 11. Principle of biogas purification 
Using two adsorption towers filled with the absorbent described above, concentrated methane with a low dew point can be seamlessly obtained by alternately repeating the adsorption and regeneration processes.

\subsubsection{Device specifications (Figure 12)}

i. Entrance biogas conditions

1. Flow rate: $3.2 \mathrm{Nm}^{3} / \mathrm{h}$

2. Pressure: $100 \mathrm{~mm} \mathrm{H}_{2} \mathrm{O}$

3. Biogas composition

$\mathrm{CH}_{4}: 60 \%, \mathrm{CO}_{2}: 40 \%$, water: saturated

Trace quantities of ingredients (e.g., hydrogen sulfide and ammonia): 1 ppm or less

ii. Exit product gas conditions

1. Methane purity: at least $95 \%$

2. Methane collection rate: at least $90 \%$

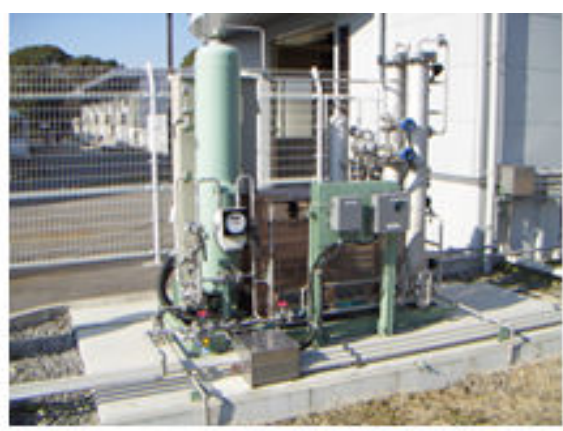

Figure 12. The adsorptive, isolated methane concentrating device

\subsubsection{Characteristics of methane concentration}

The absorbent used for methane concentration is a carbon molecular sieve (CMS) with a micropore diameter adjusted to be approximately 0.3 to $0.35 \mathrm{~nm}$ [19]. If it is used to separate carbon dioxide and methane, then the difference in adsorption rate is used instead of the difference in equilibrium adsorption capacity. Table 1 and Figure 13 show the data for the equilibrium amount adsorbed and adsorption rate curve, respectively [20]. As Figure 13 indicates, the amount of carbon dioxide reached $90 \%$ of the equilibrium adsorption capacity within one minute, while almost no methane was absorbed. This principle can be used to perform adsorption separation. 


\begin{tabular}{ccc}
\hline & $\mathrm{CO}_{2}$ & Methane \\
\hline Adsorption amount $(\mathrm{ml} / \mathrm{g})$ & 55.2 & 26.9 \\
\hline
\end{tabular}

Table 1. Equilibrium adsorption capacities (under one atmosphere pressure)

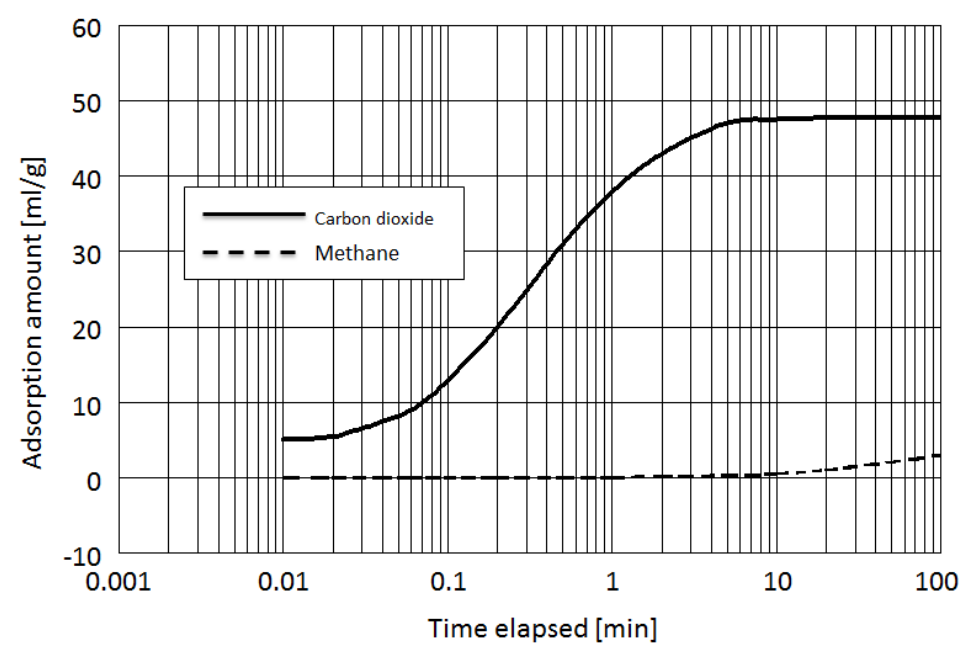

Figure 13. Adsorption rate curves for carbon dioxide and methane

\subsubsection{Operational testing for biogas}

\section{Overview}

Refined biogas can be effectively used as a fuel in vehicles and cooking appliances. In the plant, we verified the establishment of effective systems that allow biogas to be used as a fuel in light cars for food sales, service buggy cars used within the campus and for motorcycles, as well as a fuel for cooking in the cafeteria and other facilities.

Using a filler, we charged approximately 95\% biogas refined through PSA into a typical natural-gas light car, on-campus service buggy cars, motorcycles equipped with a fuel canister filled with an absorbent, and adsorptive storage cylinders for transfer filled with an absorbent. The filling equipment used charges gas under a low filling pressure of $0.98 \mathrm{MPa}$ or less, and is not, therefore, restricted by any laws or regulations in Japan.

As methane vehicles, we used on-campus light minivans, on-campus adsorptive service buggy cars, and adsorptive motorcycles. Large quantities of biogas must be stored under a high pressure. This requires adherence to the High Pressure Gas Safety Act and other laws and 
regulations, causing the unit price of biogas to rise. The system verified in this research project eliminates the need to address this matter, providing safe transfer of large volumes of biogas.

Figure 14 shows the flow chart for extracting methane from a methane adsorptive storage tank for use as a fuel in vehicles. Using these systems, biogas is expected to be able to be used in a wider range of applications, including the consumer segment.

\section{On-campus light minivans}

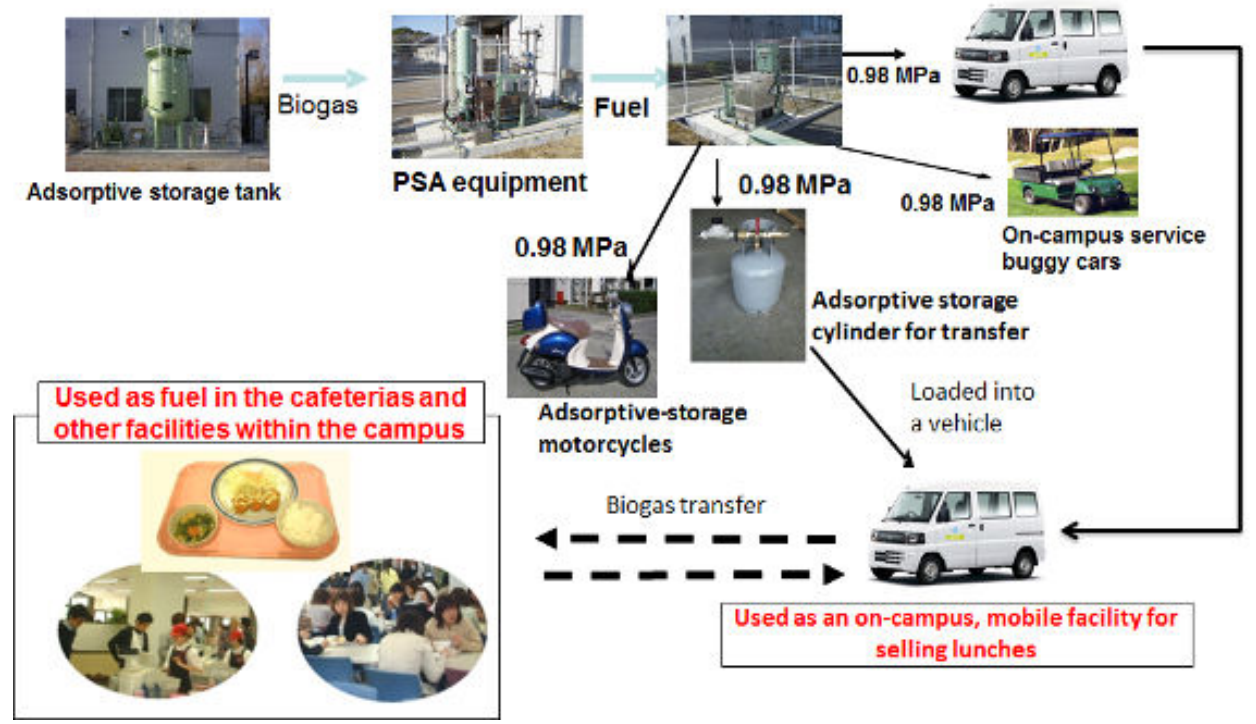

Figure 14. Flow chart for the use of biogas as a fuel in vehicles and cooking

2. Overviews of the devices

[Biogas filler] (Figure 15)

- Type

Low-pressure filling equipment for biogas

- Discharge flow rate of the gas compressor

$1.6 \mathrm{Nm}^{3} / \mathrm{h}$ or more

- Filling pressure

$0.98 \mathrm{MPa}$ G or less

- Entrance biogas composition

Methane: $95 \%, \mathrm{CO}_{2}: 5 \%$ 


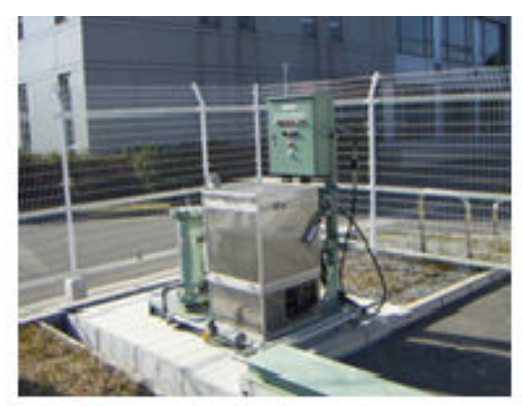

Figure 15. The biogas filler

[Light minivan] (Figure 16)

- Fuel tank

- Storage pressure

$0.98 \mathrm{MPa}$

- Storage capacity

Approx. $0.5 \mathrm{~m}^{3}$

- Travel range

$6-8 \mathrm{~km}$

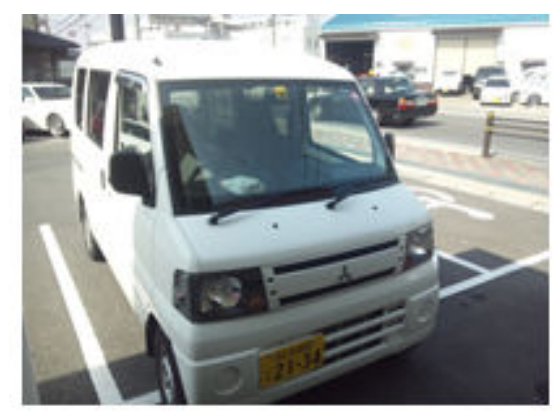

Figure 16. A light minivan

[On-campus adsorptive service buggy (Figure 17)

- Fuel tank

- Storage pressure

$0.98 \mathrm{MPa}$ 


\section{- Storage capacity}

$3.5 \mathrm{~m}^{3}$

- Travel range

$70-90 \mathrm{~km}$

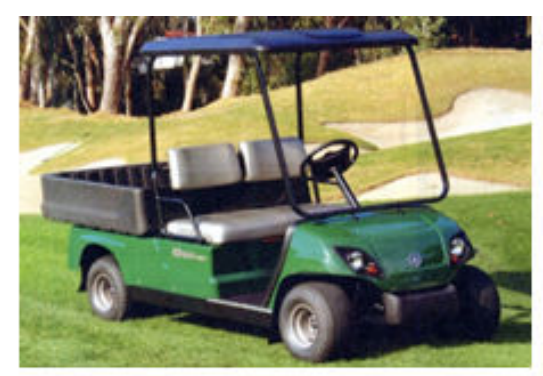

Figure 17. An on-campus adsorptive service buggy

[Adsorptive Motorcycle] (Figure 18)

- Fuel tank

- Storage pressure

$0.98 \mathrm{MPa}$

- Storage capacity

$1 \mathrm{~m}^{3}$

- Travel range

$50 \mathrm{~km}$

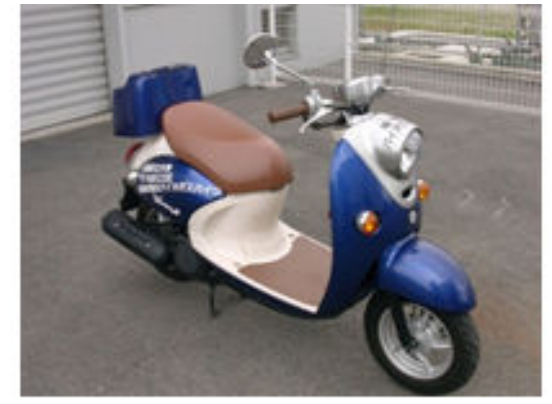

Figure 18. An adsorptive motorcycle 


\section{Conclusion}

\subsection{Consideration of business sizes}

\begin{tabular}{|c|c|c|c|c|c|}
\hline & & \multirow{2}{*}{ Motorcycle } & \multirow{2}{*}{ Buggy } & Vehicle & Vehicle \\
\hline & & & & \multicolumn{2}{|c|}{ (within the premises) (outside the premises) } \\
\hline \multicolumn{2}{|c|}{ Biogas storage capacity $\left[\mathrm{m}^{3}\right]$} & 1 & 3.5 & 0.5 & 12.5 \\
\hline \multicolumn{2}{|c|}{ Mileage [km] } & 50 & 80 & 7 & 175 \\
\hline \multicolumn{2}{|c|}{ Mileage per day [km] } & 5 & 10 & 7 & 50 \\
\hline \multicolumn{2}{|c|}{$\begin{array}{c}\text { Annual number of operation } \\
\text { days [days] }\end{array}$} & 200 & 200 & 200 & 200 \\
\hline \multicolumn{2}{|c|}{$\begin{array}{l}\text { Required monthly number of } \\
\text { cafeteria users [people] }\end{array}$} & 506 & 2212 & 2528 & 18057 \\
\hline \multicolumn{2}{|c|}{$\begin{array}{l}\text { Annual disposal amount of } \\
\text { glycerin }[\mathrm{L}]\end{array}$} & 9.74 & 42.6 & 48.7 & 348 \\
\hline \multirow{3}{*}{$\begin{array}{l}\text { Annual } \\
\text { reduction of } \mathrm{CO}_{2} \\
\text { emissions }[\mathrm{kg}]\end{array}$} & BDF & 170 & 744 & 850 & 6075 \\
\hline & Biogas & 44.1 & 193 & 221 & 1577 \\
\hline & Total & 214 & 937 & 1071 & 7651 \\
\hline \multicolumn{2}{|c|}{ Use } & Delivery of mail, etc. & $\begin{array}{l}\text { Travel within the } \\
\text { premises }\end{array}$ & $\begin{array}{c}\text { Material } \\
\text { transportation } \\
\text { within the premises }\end{array}$ & $\begin{array}{c}\text { Material } \\
\text { transportation } \\
\text { from/to the premises }\end{array}$ \\
\hline
\end{tabular}

Table 2. Utilizations of biogas and their effects on $\mathrm{CO}_{2}$ emissions reduction

Based on numerical values regarding biogas uses and utilizations (from product catalog data), we considered the required business sizes.

In the model, we used the number of users of the co-op cafeteria and the amount of waste cooking oil generated. The co-op cafeteria of Osaka Prefecture University is used by 23,000 people per month on average and 3,000 liters of waste cooking oil are discharged annually. We considered the amount of glycerin derived from BDF production to be one quarter of the amount of waste cooking oil. Table 2 summarizes the uses and utilizations of the biogas along with their effects on $\mathrm{CO}_{2}$ emissions reduction.

Based on the data in the table, we estimated that the business model proposed by this research can be applied to any business place that has a dining facility used by hundreds of people a month. With increases in the number of users, the form of use and utilization develops; if a business place has a dining facility or facilities used by more than 20,000 people a month, then it is expected that the business can expand the use range to include the utilization of business vehicles. 
Brazil, an excellent exemplar for biomass energy power generation, has started to make efforts to reduce fossil fuel use by blending 10\% BDF into light oil, similar to the use of bioethanol in the past. The process proposed can be applied to all vehicles, including natural-gas and diesel vehicles, as long as they use an internal combustion engine. The largest challenge is fuel storage. Because gas changes volume with temperature, it is important to increase the amount of biogas stored per unit volume. Our partner, Osaka Gas Engineering, owns leading-edge technology for biogas storage and its application, which is expected to popularize the business model.

\subsection{Future challenges}

Below are the future challenges associated with business projects that use biogas as a fuel and other uses:

1. Decreasing the fuel price per unit heating value to or below that of city gas

In many cases, the use of biogas as a fuel is compared with the use of city gas in terms of cost because they exhibit similar properties [21]. The comparison, however, normally indicates that biogas has no clear advantage.

On the other hand, to achieve sustainable development, it is important to use biogas - a recyclable, carbon-neutral fuel. For this reason, it is necessary to give a preferential tax rate according to its use and implement a system that facilitates subsidies for equipment installation, for example.

2. Developing a comprehensive plan covering the entire surrounding area when constructing a biogas generation facility

To use biogas, a waste-derived fuel, at low cost, it is imperative that the raw material (waste) can be collected intensively and that local facilities can use the generated biogas. This means that it is necessary to develop a comprehensive plan covering all neighboring areas when constructing a biogas generation facility.

Based on the characteristics of the university, this research covers all processes ranging from the generation of waste and the production of biogas and BDF to their uses, so it may provide an excellent case study for developing a regional plan.

3. Eliminating restrictions to the use of biogas through fuel transfer, based on an adsorptive storage technology

Currently, the sewage plants in Osaka city use sludge digestion to dispose of sludge. For the effective use of the biogas generated there, electric power generation and many other applications are being considered and implemented.

On the other hand, when sewage plants and other facilities make effective use of biogas, that use is subject to many laws and regulations (e.g., High Pressure Gas Safety Act, Gas Business Act, and Building Standards Act), depending on the installation site, and therefore is restricted in some cases. If electric power is generated within the premises of a sewer plant, the generation efficiency is lower than that of large electric power generation 
facilities, and the location where the collected hot water should be used must be considered.

The biogas transfer system based on the adsorptive storage technique is an effective solution to these problems.

Examples of useful applications may include a sewer plant or a methane fermentation facility that cannot make effective use of biogas because it is located in a non-industrial area; biogas generated there can be transferred to a large electric power generation facility using an adsorptive storage tank installed in an ISO-defined container for use as a fuel. In this case, the use of biogas is not subject to the various laws and regulations and it is possible to safely transfer large volumes of biogas. Biogas has similar properties to natural gas and can be used at power plants and other facilities that use natural gas as fuel. Therefore, its use is expected to grow.

\section{Acknowledgements}

This research was conducted with the considerable help of Professor Taketoshi Okuno, President of Osaka Prefecture University, and Professor Masakazu Ampo, Vice-President of the university. In addition, the research was subsidized by Osaka City as a project to help verify the practicality of environmental and energy-related technologies. We would like to express our heart-felt thanks to all of the above.

\section{Author details}

Hayato Tokumoto ${ }^{1 *}$, Hiroshi Bandow ${ }^{1}$, Kensuke Kurahashi ${ }^{2}$ and Takahiko Wakamatsu ${ }^{3}$

*Address all correspondence to: tokumoto@chemeng.osakafu-u.ac.jp

1 Department of Chemical Engineering, Osaka Prefecture University, Gakuen-cho, Sakai, Osaka, Japan

2 Osaka Prefecture University College of Technology, Saiwai, Neyagawa, Osaka, Japan

3 Energy and Environment Business Div, Energy Business and Engineering Dept, Osaka Gas Engineering Co., Ltd., Japan

\section{References}

[1] Yazdani, S.S, Gonzalez, R. Anaerobic fermentation of glycerol : a path to economic viability for the biofuels industry. Current Opinion in Biotechnology 2007;18(3) 213-219. 
[2] Choi W J. Glycerol-Based Biorefinery for Fuels and Chemicals. Recent Patents on Biotechnology 2008;2(3) 173-180.

[3] Siles López J.A, Martín Santos M.d.l.A, Chica Pérez A.F, Martín Martín A. Anaerobic digestion of glycerol derived from biodiesel manufacturing. Bioresource Technology 2009;100(23) 5609-5615.

[4] Gunaseelan, V.N. Anaerobic digestion of biomass for methane production: A review. Biomass and Bioenergy 1997;13(1-2) 83-114.

[5] Willke Th, Vorlop K.-D. Industrial bioconversion of renewable resources as an alternative to conventional chemistry. Applied Microbiology and Biotechnology 2004;66(2)131-142.

[6] Nishio N, Nakashimada Y. Recent Development of Anaerobic Digestion Processes for Energy Recovery from Wastes. Journal of Bioscience and Bioengineering 2007;103(2) 105-112.

[7] Yang Y, Tsukahara K, Sawayama S. Biodegradation and methane production from glycerol-containing synthetic wastes with fixed-bed bioreactor under mesophilic and thermophilic anaerobic conditions. Process Biochemistry 2008;43(4) 362-367.

[8] Bagi Z, Ács N, Bálint B, Horváth L, Dobó K, Perei K R, Rákhely G, Kovács K.L. Biotechnological intensification of biogas production. Applied Microbiology and Biotechnology 2007;76(2) 473-482.

[9] Johnson D T, Taconi K A. The Glycerin Glut: Options for the Value-Added Conversion of Crude Glycerol Resulting from Biodiesel Production. Environmental Progress 2007;26(4) 338-348.

[10] Temudo M F, Poldermans R, Kleerebezem R, Van Loosdrecht M C M. Glycerol Fermentation by (Open) Mixed Cultures: A Chemostat. Study. Biotechnology and Bioengineering 2008;100(6,15)1088-1098.

[11] da Silva G P, Mack M, Contiero J. Glycerol: A promising and abundant carbon source for industrial microbiology. Biotechnology Advances 2009;27(1)30-39.

[12] Chatzifragkou A, Makri A, Belka A, Bellou S, Mavrou M, Mastoridou M, Mystrioti P, Onjaro G, Aggelis G, Papanikolaou S. Biotechnological conversions of biodiesel derived waste glycerol by yeast and fungal species. Energy 2011;36(2) 1097-1108.

[13] Pagliaro M, Ciriminna R, Kimura H, Rossi M, Della Pina C. From Glycerol to ValueAdded Products. Angewandte Chemie - International Edition 2007;46(24)4434-4440.

[14] Fernando S, Adhikari S, Kota K, Bandi R. Glycerol based automotive fuels from future biorefineries. Fuel 2007;86(17-18)2806-2809.

[15] Sosnowski P, Wieczorek A, Ledakowicz S. Anaerobic co-digestion of sewage sludge and organic fraction of municipal solid wastes. Advances in Environmental Research 2003;7(3) 609-616. 
[16] Ministry of the Environment, Government of Japan. http://www.env.go.jp/policy/chieno-wa/download/0502/0502d-2.pdf

[17] Esteves I, Lopes M, Nunes P, Mota J. Adsorption of natural gas and biogas components on activated carbon. Separation and Purification Technology 2008:62 281-296

[18] Carter J W, Wyszynski M L. The pressure swing adsorption drying of compressed air. Chemical Engineering Science 1983;38(7) 1093-1099

[19] Ruthven D M. Principles of Adsorption and Adsorption Processes (10th Ed.). New York: John Wiley; 1984.

[20] Itoga K: Abe Y, Tachimoto H, editor. Kasseitan no Ohyohgijutsu. Tokyo: Technosystem Co, Ltd; 2000. P226

[21] Patterson T, Esteves S, Dinsdale R, Guwy A. An evaluation of the policy and technoeconomic factor affecting the potential for biogas upgrading for transport fuel use in the UK. Energy Policy 2011:39 1806-1816 
